\title{
Organizational Culture and the Organizational Commitment; Correlational Study in Hospital Staffs
}

\author{
Hojjat Rahmani ${ }^{1}$, Samad Azari ${ }^{2}$, Ghasem rajabi Vasokolaee ${ }^{3,4}$, Masood Taheri Mirghaed ${ }^{4} \&$ Mehdi Raadabadi $^{5}$ \\ ${ }^{1}$ Health Care Management Department, School of Allied Medicine, Tehran University of Medical Sciences, \\ Tehran, Iran \\ ${ }^{2}$ Health Management and Economics Research Center, Iran University of Medical Sciences, Tehran, Iran \\ ${ }^{3}$ Student Scientific Research Center, School of Allied Medicine, Tehran University of Medical Sciences, Tehran, \\ Iran \\ ${ }^{4}$ Student Scientific Research Center, School of Public Health, Tehran University of Medical Sciences, Tehran, \\ Iran \\ ${ }^{5}$ Research Center for Health Services Management, Institute for Futures Studies in Health, Kerman University \\ of Medical Sciences, Kerman, Iran
}

Correspondence: Mehdi Raadabadi, Kerman University of Medical Sciences, Haftbagh St. Kerman, Iran. Tel: 98-913-451-8067. E-mail: mehdiraadabadi@gmail.com

Received: October 6, 2014 Accepted: November 16, 2014 Online Published: February 12, 2015

doi:10.5539/ass.v11n5p143 URL: http://dx.doi.org/10.5539/ass.v11n5p143

\begin{abstract}
Organizations need the committed manpower to provide effectiveness and progress which is an important factor in order to achieve organizational goals. According to this, organizational culture increases employees commitment in the organization by their accepted norms and values. Actually, the organization environment \& its prevailing culture, affects on the organizational commitment of staff. This study was conducted to assess relationship between the organizational culture and the organizational commitment among staff of elected hospirals in Tehran University of Medical Sciences.

This descriptive study accomplished at 2013. The study population was hospitals affiliated to Tehran University of Medical Sciences included the two hospitals "Vali Asr" \& "farabi". Also in hospitals, study populations were all hospital staffs (Administrative and Clinical). Data collection was done using a three parts questionnaire including: the first one contains background information, the second part consists of questions related to organizational culture based on Denison model and the third part includes questions related to organizational Commitment based on Porter model. Validity and reliability were confirmed through getting the opinions of experts and using Cronbach's alpha.
\end{abstract}

Data analysis was done by SPSS software using Pearson correlation test and the test " $\mathrm{t}$ " to determine the relation between the areas of culture and commitment to the type of hospitals.

In organizational culture, maximum average \& standard deviation has been seen in professional identity (4.74 \pm 1.38$)$. Except for the two dimentions of conflict \& communication patterns, a significant relation between the organizational culture dimentions and two hospitalas was seen. Also, in the organizational commitment, the maximum average \& standard deviation was seen in continuous commitment scope. Overally, average \& standard deviation (3.18 \pm 0.76$)$ has been obtained for organizational commitment component; also there was significant relation between the emotional commitment dimention \& the type of the hospital. This relationship wasn't meaningful in another dimentions. Except for the conflict dimension, there was significant correlations between the organizational culture dimension\& the organizational commitment $(\mathrm{p}<0.05)$. Also, this correlation was between the organizational culture and the organizational commitment $(\mathrm{r}=0.552)$

Designing an appropriate and justified "reward mechanism" and development of "teamwork" skills between employees can increase their organizational commitment positively and improve hospital performances.

Keywords: organizational culture, organizational commitment, hospital staff, Denison 


\section{Introduction}

Efficiency achievement is one of the main goals of any organization. To achieve this goal, a systemic, native and applied approach is required. Success of organizations with the minimum facilities \& Failure of organizations with the best possibilities in recent decades indicate the significant role of non-material and spiritual factors in organizations(Cameron \& Quinn, 2011). On the other hand, Organizations need to expert, skilled, committed \& qualified staff to the organization and apply their extreme degree of precision for perform their duties to manage the tasks,. Failure to Creating coherence and union among the members in the Organization increases necessary expenses required to precise control. Hence, organizations with employees which internalized the values and goals and believe the values and the goals on themselves, assures that act in order to serve the interests of the organization(Mowday, Steers, \& Porter, 1979).

Nowadays, change and transformation rapidly grow in the world and in this variable and complex environment, those organizations will be successful that are able to adapt to these changes. One of the major factors to this is the Organizational culture, because of dependence of Strategy implementation on organizational culture. Organizational culture is a set of features that distinguish an organization from other one. As the personality refers to the individual's fundamental characteristics, culture also relates to organizations stable features (Karaminia, Salimi, \& Amini, 2010). Denison believes that organizational culture refers to basic values, beliefs and principles serves to management system as a firm foundation (Denison, Janovics, Young, \& Cho, 2006). Organizational culture that is the sub product of social culture impresses individual's values, morality, attitudes, defaults and expectations and appears in his or her behavior(Beekun \& Badawi, 2005). Organizational culture causes unity \& cohesion in the organization, so a weak organizational culture ,pack organization and unhealthy atmosphere causes staff disappointment and stress resulting in frustration and pessimism in employees towards themselves and the others and ultimately productivity reduction \& dissatisfaction(Shamsudin, Kasim, Hassan, \& Johari, 2010).

Organizational culture acts as a social control system (Bate, 2000) and managers get a more complete awareness of the atmosphere governing over organization, organization's strengths and weaknesses; and identify and apply required strategy and policies (Kwantes \& Boglarsky, 2007; Zheng, Yang, \& McLean, 2010). By a strong and coherent culture, individuals are aware of the organization goals and strategies and feel responsible in relation to values and norms and finally results in the commitment and job satisfaction (Chan, Shaffer, \& Snape, 2004). After considering other methods of investigating organizational culture, the authors decided that to use Denison's model for this study. The reasons why we choose this model is that, because this is more modern than previous models, it is based on behavior, it can be used at all levels of or the organization its indexes of measurement are complete and it evaluates different model is its graphic diagram that specifies features of organizational culture in 12 indices, Also it contains two vertical and horizontal axis that dived this model into four quadrants. Vertical axis contains degree and kind of organizational culture, this axis ends at one side to External focus and at the other end to internal focus. The horizontal axis shows the flexibility of the organization.

This axis end at one end to stable culture and at the other end of the flexible culture(Denison, 2000).

Another spiritual factor in organizations' situation is the committed human forces. Organizational commitment is defined as an organization's identification intensity and his partnership and cooperation with his or her organization .Robins introduces organizational commitment as a kind of occupational attitude that the organization members recognizes the goals of organization as his representative and wishes to remain in the organization membership; so in order to achieve organizational goals, he does all his efforts and impresses organization performance (Saatchi M, 2009). Individual's commitment is concerned not only to their work but also their values and beliefs (Dwyer, Richard, \& Chadwick, 2003). The more committed staffs, are more bounded to the organization values and goals, perform their role more actively and also less attempt to leave the organization and find new job opportunities (Maurer \& Lippstreu, 2008). However there is a small number of empirical studies a relationship between organizational culture and commitment has often been theoretically proposed. Yilmaz and Ergan (2008), Studied the impact of Denison's culture organization model for the organization's performance. Results showed that adaptability culture had maximum score and consistency culture had minimum score (Yilmaz \& Ergun, 2008). Mobely et al. (2005), studied Denison's model in the different Chinese organization. In furniture maker organizations maximum score belonged to vision index and the minimum score belonged to capability development. In insurance companies organizational learning index was high and the customer focus index was lower (Mobley, Wang, \& Fang, 2005). Ardalan et al. (2009), in their study tried to study the relationship between organizational culture with Person-Organization Fit with the help of Denison's model in the state universities of west of Iran. They showed that all of 4 cultural dimensions of Denison's model exist in west of Iran State- Universities (Ardalan, Salimi, Rajaeepour, \& Molavy, 2008). 
To achieve more organizational commitment, managers should try strive the organization involve the staff's values. This means that the management must take an effort to enrich the culture of his organization (Ooi \& Arumugam, 2006). Health system managers are not also exempt from this rule. Regarding to this matter, Hospitals also are considered as one the major institutions providing health care services and perform important role in maintenance, return and improving patients' physical and mental health, can have more dynamic and more flexible organizational structure. Since hospitals in terms of social situation in societies, need to assess their cultural features and organizational commitment among staffs. Therefor the researchers aimed to examine the relationship between organizational culture and organizational commitment among staff in different hospitals of Tehran University of Medical Sciences.

\section{Method}

This Discriptive study was done at 2013. The population study was hospitals affiliated to Tehran University of Medical Sciences which two hospitals "Vali Asr" \& "Farabi" were chosen. Hospitals affiliated to Tehran University of Medical Sciences divided into two sub groups of general and specialized hospitals and then using simple random selection, a general and a specialized hospital chose. A Vali Asr hospital with different types of services (General Hospital) and a Farabi hospital with only one aspect of care (specialized hospital). In the studied hospitals also the study population included all the two hiospitals' staff (Administrative and Clinical). Among 544 and 831staffs respectively in "Farabi" \& "Vali Asr" hospital, according to Cochran samoling formula, 300 sample intered the study and finally 246 questionnate were returned (returen rate 82 percentage). Staff selection was done using stratified samling: this way that employees divided into various classes depending on job field (therapy, administrative, paraclinic, ....) and employees was selected as a proportion of each class and then used simple random among each class. A questionnate used in this study to collect data. The questionnaire included three parts. The first part comprised background information (age, gender, years of working, study field, organizational position), the secon part included the questions related to organizational culture based on Denison model (innovation, Risk taking, Leadership, Integration, Management support, controling, corporate identity, Reward System, Communication patterns and compromise with the conflict) and the third section included the questions related to the organizational commitment based on Porter Proposed Model. The questions concerned to organizatinal culture and commitment measured based onfive scales Likert style which $1=$ very low $\& 5=$ very much. The validity of the questionnaire was confirmed through getting the opinions of faculty members of the questionnaire. Also its reliability was confirmed using Cronbach's alpha (83 percents for organizational culture's and 73 percents for organizatonal commitment). Data analized using the 19th Edition SPSS software. Pearson Correlation was used to assess the correlation of organizatinal culture and staff commitment. Also, the test " $\mathrm{t}$ " used to determine the relation between the culture and commitment areas with type of the hospital. Also a meaningful level less than 0.05 was considered in all tests. 2.1 Identify Subsections

\section{Results}

Table 1. Demographic variables of staffs participating in study

\begin{tabular}{cccccc}
\hline \multirow{2}{*}{ Variable } & \multirow{2}{*}{ type } & \multicolumn{2}{c}{ Hospital A } & \multicolumn{2}{c}{ Hospital B } \\
\cline { 2 - 6 } & & Frequency & percent & Frequency & percent \\
\hline \multirow{2}{*}{ Marriage } & single & 37 & 15 & 25 & 10.2 \\
& Married & 94 & 38.2 & 184 & 74.8 \\
Sex & male & 50 & 20.3 & 54 & 22 \\
& famale & 81 & 32.9 & 61 & 24.8 \\
& Diploma & 16 & 6.5 & 24 & 9.8 \\
Education & Associate & 13 & 5.3 & 15 & 6.1 \\
& Bachelor & 83 & 33.7 & 54 & 22 \\
& Master & 19 & 7.7 & 22 & 8.9 \\
& $20-30$ & 61 & 25.1 & 31 & 12.8 \\
Age & $31-40$ & 31 & 12.8 & 50 & 20.6 \\
& $41-50$ & 30 & 12.3 & 27 & 11.1 \\
& $51-60$ & 7 & 2.9 & 6 & 2.5 \\
\hline
\end{tabular}

Of the total staffs participated in study in Hospital A and according to marriage status, $15 \%$ were single and $38.2 \%$ were married, in terms of gender $20.3 \%$ were males and $32.2 \%$ were females , most of them $(33.7 \%)$ were in Bachelor degree and maximum Age group was between 20 to 30. In the hospital B and according to marriage 
status $10.2 \%$ were single and $74.8 \%$ were married. In terms of gender also the most individuals were $24.8 \%$ were females, $9.8 \%$ with high education level, $20.6 \%$ were in the range of 30 to 40years (Table 1 ).

Table 2. Average and standard deviation of organizational culture dimensions in two hospitals

\begin{tabular}{|c|c|c|c|c|}
\hline dimension & hospital & mean & Standard deviation & P-value \\
\hline \multirow[t]{3}{*}{ innovation } & Hospital A & 2.70 & 0.78 & 0.001 \\
\hline & B & 2.32 & 0.65 & \\
\hline & Total & 2.55 & 0.75 & \\
\hline \multirow[t]{3}{*}{ risk taking } & A & 2.52 & 0.69 & 0.002 \\
\hline & B & 2.19 & 0.75 & \\
\hline & Total & 2.39 & 0.73 & \\
\hline \multirow[t]{3}{*}{ Leadership } & A & 2.09 & 0.71 & 0.004 \\
\hline & B & 2.56 & 0.55 & \\
\hline & Total & 2.88 & 0.70 & \\
\hline \multirow[t]{3}{*}{ Integration } & A & 2.92 & 0.73 & 0.003 \\
\hline & B & 2.55 & 0.67 & \\
\hline & Total & 2.77 & 0.73 & \\
\hline \multirow[t]{3}{*}{ Management support } & A & 2.83 & 0.89 & 0.001 \\
\hline & B & 2.30 & 0.63 & \\
\hline & Total & 2.62 & 0.83 & \\
\hline \multirow[t]{3}{*}{ controlling } & A & 3.01 & 0.51 & 0.002 \\
\hline & B & 2.69 & 0.62 & \\
\hline & Total & 2.88 & 0.58 & \\
\hline \multirow[t]{3}{*}{ corporate Identity } & A & 5 & 1.29 & 0.001 \\
\hline & B & 4.34 & 1.43 & \\
\hline & Total & 4.47 & 1.38 & \\
\hline \multirow[t]{3}{*}{ Reward System } & A & 3.03 & 0.59 & 0.000 \\
\hline & B & 2.66 & 0.52 & \\
\hline & Total & 2.88 & 0.59 & \\
\hline \multirow[t]{3}{*}{ Communication patterns } & A & 2.74 & 0.64 & 0.216 \\
\hline & B & 2.62 & 0.61 & \\
\hline & Total & 2.69 & 0.63 & \\
\hline \multirow[t]{3}{*}{ Conflict } & A & 2.93 & 0.40 & 0.892 \\
\hline & B & 2.92 & 0.55 & \\
\hline & Total & 2.93 & 0.46 & \\
\hline \multirow[t]{3}{*}{ Organization Culture } & A & 2.89 & 0.47 & 0.001 \\
\hline & $\mathrm{B}$ & 2.57 & 0.42 & \\
\hline & Total & 2.76 & 0.47 & \\
\hline
\end{tabular}

The maximum average and standard deviation observed in corporate identity ( $4.74 \pm 1.38$ ). A significant relationship observed between two hospitals and the organizational culture dimentions, except for the two of the conflict \& cummunication patterns ( Table 2).

Table 3. Average and the standard deviation of the organizational commitment component in two hospitals

\begin{tabular}{ccccc}
\hline & Hospital & Mean & Standars Deviation & P-Value \\
\hline Normative & Hospital A & 2.97 & 0.45 & 0.205 \\
Commitment & Hospital B & 2.88 & 0.39 & \\
& Totall & 2.93 & 0.42 & 0.004 \\
Affective Commitment & Hospital A & 3.02 & 0.65 & \\
& Hospital B & 2.76 & 0.53 & 0.097 \\
& Totall & 2.91 & 0.61 & \\
Continuance & Hospital A & 3.60 & 1.44 & 0.130 \\
Commitment & Hospital B & 3.23 & 1.20 & \\
& Totall & 3.48 & 0.37 & \\
Organizational & Hospital A & 3.25 & 0.64 & \\
Commitment & Hospital B & 3.06 & 0.76 & \\
& Totall & 3.18 & &
\end{tabular}


In Table 3 average and the standard deviation of the organizational commitment dimension has been shown in two hospitals. Maximum avarage and standard deviation observed in continuous commitment area.Totally average and standard deviation of $3.18 \pm 0.76$ obtained for the organizational commitment dimentions. Also there wasn'y any significant relation between the emotional commitment and the type of the hospital. This relation wasn't significant in the other two fields.

Table 4. relationship between the organizational culture dimentions with the organizational commitment

\begin{tabular}{ccc}
\hline \multirow{2}{*}{ Organization Culture (dimention) } & \multicolumn{2}{c}{ Organizational Commitment } \\
\cline { 2 - 3 } & Pearson correlation & P-value \\
\hline innovation & 0.333 & 0.001 \\
risk taking & 0.339 & 0.001 \\
Leadership & 0.443 & 0.002 \\
Integration & 0.458 & 0.001 \\
Management support & 0.451 & 0.004 \\
controlling & 0.428 & 0.002 \\
corporate Identity & 0.569 & 0.001 \\
Reward System & 0.352 & 0.003 \\
Communication pattern & 0.430 & 0.004 \\
Conflict & -0.024 & 0.776 \\
Organization Culture & 0.552 & 0.000 \\
\hline
\end{tabular}

A significant correlation was between the organizational culture dimensions and organizational commitment component except for the conflict dimension $(\mathrm{p}<0.05)$.Also this correlation was between the two components of organizational culture and Commitment $(\mathrm{r}=0.552)$ (Table 4).

\section{Discussion}

The aim of this study was assessing relation between the organizational culture \& commitment among hospital staffs of two hospitals of Tehran University of Medical Sciences in 2012 Denison Organizational Culture Model. The results of study showed that there is a positive and signuificant relationship between the organizational culture \& organizational commitment; i.e. the culture of an organization indicates individual's attitude towards the organization and this way of attitude will be effective on individual's behaviour in working environment. Ziaeeyan et al. confirms our results in their study that accomplished amongst Tehran University library staff. He introduced that an organization staff is greatest wealth and success of organizations depends on powerful and efficient staffs. staff efficiency and the type of values governing the organization that causes individuals movement in the organization and has pervasive effect on organization components ; then if members of an organization have common goals, values and beliefs, feel an emotional attachment to them finally and results in remaining committed and loyal towards the oraganization. In this research also relationship between organizational culture and staff commitment and library managers approved (Zeiaee, 2011). Also founds of Ghayour et al. (GHayur, 2008), Ameli et al. (Ameli, 2011), Nassiri pour (Nasiripour, 2009) and Maleki (Maleki, 2008) agree results of our study and is compatible with them. In this study there wasn't seen any positive and meaningful relationship just between conflict dimension and organizational commitment but there's a positive and significant relation in other dimensions. Results of the Ameli study also indicated that there's a meaningful and positive relation between innovation dimensioned organizational commitments(Ameli, 2011). Regarding the dimension of reward system, Driscoll and Randol say that rewards given to staffs by the organization have a significant effect in their commitment to their organization (O'Driscoll \& Randall, 1999). In a study on 532 nurses Van Hessin Hoo et al, came to this result that job satisfaction has a positive effect on their organizational commitment (Boswell, Boudreau, \& Tichy, 2005). Arshadi also reached to the similar results in his study (Arshadi, 2011) Proving of similar relation in the present study indicates that we can increase staff organizational commitment by formulating an appropriate reward mechanisms resulting in improving performance. There's a meaningful relation between dimension of organizational communication and staff commitment. Many authors showed a similar results but no such a result observed in Maleki et al study (Brunetto \& Farr-Wharton, 2004; Goris, Vaught, \& Pettit, 2000). Through proper communication, the organization goals are announced to staffs that the way of this communication and notifying it affect the organizational commitment. Also the study results showed that there's a positive and significant relation between the organizational commitments dimensions i.e. emotional commitment, continuous Commitment and assignment commitment with the organizational culture. The measure of this correlation is weaker for assignment commitment and the stronger for emotional and 
contnuous commitment. The results of study showed that assignment commitment in these organizations is at higher priority to the other aspects and dimensions and can be exploited as a positive point for proper use of human resources. Sayyed Morteza Ghayour et al. also achieved similar results in their studies with this difference that their study suggested the correlation is stronger for the assignment Commitment and is weaker for the continuous \& emotional commitment, respectively (GHayur, 2008).

\section{Conclusions}

Regarding to the results which showed the priority of the factors organizational culture and commitment, corporate identity and reward system has a greater role in the development of organizational commitment, compared with the other considered variables, in the view of staff. Thus, hospitals can use these factors to increase staff loyalty. Also about the organizational commitment dimensions, the results of the study, suggests that continuous commitment in these hospitals stands in higher priority rather than other aspects and dimensions so that can show a positive point in proper using of human resources.

\section{Acknowledgments}

The Authors would like to thank all participants for their kind cooperation with the researchers in collecting the data.

\section{References}

Ameli, A. A. (2011). The relationship between organizational culture and employees' organizational commitment. Journal of taxes and development, 5(11), 108-128.

Ardalan, M. R., Salimi, Q., Rajaeepour, S., \& Molavy, H. (2008). A study of Relationship between Person-Organization Fit and Organizational Culture in Western Iran State Universities) Hamedan, Kermanshah and Kordestan). Quarterly journal of Research and Planning in Higher Education, 14(1), 97-131.

Arshadi, N. (2011). The relationships of perceived organizational support (POS) with organizational commitment, in-role performance, and turnover intention: Mediating role of felt obligation. Procedia Social and Behavioral Sciences, 30, 1103-1108. http://dx.doi.org/10.1016/j.sbspro.2011.10.215

Bate, P. (2000). Changing the Culture of a Hospital: From Hierarchy to NetworkedCommunity. Public Administration, 78(3), 485-512. http://dx.doi.org/10.1111/1467-9299.00215

Beekun, R. I., \& Badawi, J. A. (2005). Balancing ethical responsibility among multiple organizational stakeholders: the Islamic perspective. Journal of business ethics, 60(2), 131-145. http://dx.doi.org/10.1007/ s10551-004-8204-5

Boswell, W. R., Boudreau, J. W., \& Tichy, J. (2005). The relationship between employee job change and job satisfaction: the honeymoon-hangover effect. Journal of applied psychology, 90(5), 882. http://dx.doi.org/10.1037/0021-9010.90.5.882

Brunetto, Y., \& Farr-Wharton, R. (2004). Does the talk affect your decision to walk: A comparative pilot study examining the effect of communication practices on employee commitment post-managerialism. Management Decision, 42(3/4), 579-600. http://dx.doi.org/10.1108/00251740410518976

Cameron, K. S., \& Quinn, R. E. (2011). Diagnosing and changing organizational culture: Based on the competing values framework. John Wiley \& Sons.

Chan, L. L., Shaffer, M. A., \& Snape, E. (2004). In search of sustained competitive advantage: the impact of organizational culture, competitive strategy and human resource management practices on firm performance. The International Journal of Human Resource Management, 15(1), 17-35. http://dx.doi.org/10.1080/ 0958519032000157320

Denison, D. R. (2000). Organizational culture: Can it be a key lever for driving organizational change. In The international handbook of organizational culture and climate (pp. 347-372).

Denison, D. R., Janovics, J., Young, J., \& Cho, H. J. (2006). Diagnosing organizational cultures: Validating a model and method. Documento de trabajo. Denison Consulting Group.

Dwyer, S., Richard, O. C., \& Chadwick, K. (2003). Gender diversity in management and firm performance: the influence of growth orientation and organizational culture. Journal of Business Research, 56(12), 1009-1019. http://dx.doi.org/10.1016/S0148-2963(01)00329-0

GHayur, S. M. T. N. (2008). Investigation of Relation between Organizational Culture and Organizational 
Commitment: Case study of Ferdosi Mashhad university. Department of management, University of Imam Reza, 3(5), 34-37.

Goris, J. R., Vaught, B. C., \& Pettit, J. D. (2000). Effects of communication direction on job performance and satisfaction: a moderated regression analysis. Journal of Business Communication, 37(4), 348-368. http://dx.doi.org/10.1177/002194360003700402

Karaminia, R., Salimi, S. H., \& Amini, A. (2010). Relation between leadership style and organizational culture and commitment in military forces. MilMed Journal, 12(2), 65-70.

Kwantes, C. T., \& Boglarsky, C. A. (2007). Perceptions of organizational culture, leadership effectiveness and personal effectiveness across six countries. Journal of International Management, 13(2), 204-230. http://dx.doi.org/10.1016/j.intman.2007.03.002

Maleki, M, B. M., \& Gholamalipour, S. (2008). The relationship between organizational culture dimensions and employees' organizational commitment in Shahid Saddoghi Hospital - Yazd; 2006. JHA, 8(22), 67-73.

Maurer, T. J., \& Lippstreu, M. (2008). Who will be committed to an organization that provides support for employee development? Journal of Management Development, 27(3), 328-347. http://dx.doi.org/10.1108/ 02621710810858632

Mobley, W. H., Wang, L., \& Fang, K. (2005). Organizational culture: Measuring and developing it in your organization. Harvard Business Review China, 3, 128-139.

Mowday, R. T., Steers, R. M., \& Porter, L. W. (1979). The measurement of organizational commitment. Journal of vocational behavior, 14(2), 224-247. http://dx.doi.org/10.1016/0001-8791(79)90072-1

Nasiripour, A. R. P., \& Hedayati, S. (2009). The Relationship between Organizational Cultures and Employees Productivity. JHA, 12(35), 17-24.

O'Driscoll, M. P., \& Randall, D. M. (1999). Perceived organisational support, satisfaction with rewards, and employee job involvement and organisational commitment. Applied Psychology, 48(2), 197-209. http://dx.doi.org/10.1111/j.1464-0597.1999.tb00058.x

Ooi, K. B., \& Arumugam, V. (2006). The influence of corporate culture on organizational commitment: case study of semiconductor organizations in Malaysia. Sunway Academic Journal, 3, 99-115.

Saatchi, M. G. N., \& Namazi S. (2009). An investigation into the relationship between principals' job motive and job satisfaction and organizational commitment of Marvdasht high school teachers. Quarterly Journal of New Approaches in Educational Administration, 1(2), 153-175.

Shamsudin, A., Kasim, A., Hassan, M. G., \& Johari, N. A. (2010). Preliminary insights on the effect of Islamic work ethic on relationship marketing and customer satisfaction. The Journal of Human Resource and Adult Learning, 6(1), 106-114.

Yilmaz, C., \& Ergun, E. (2008). Organizational culture and firm effectiveness: An examination of relative effects of culture traits and the balanced culture hypothesis in an emerging economy. Journal of world business, 43(3), 290-306. http://dx.doi.org/10.1016/j.jwb.2008.03.019

Zeiaee, M. S. R. T., \& Nargesian, A. (2011). Investigation of Relation between Organizational Culture and Organizational Commitment in Libraries Personnel of University of Tehran: Based on Dennison's Organizational Culture Model. Journal of Academic Librarianship and Information Research, 45(55), 49-72.

Zheng, W., Yang, B., \& McLean, G. N. (2010). Linking organizational culture, structure, strategy, and organizational effectiveness: Mediating role of knowledge management. Journal of Business Research, 63(7), 763-771. http://dx.doi.org/10.1016/j.jbusres.2009.06.005

\section{Copyrights}

Copyright for this article is retained by the author(s), with first publication rights granted to the journal.

This is an open-access article distributed under the terms and conditions of the Creative Commons Attribution license (http://creativecommons.org/licenses/by/3.0/). 